Mariana Bandeira Formiga

(ㄱ) https://orcid.org/0000-0003-0844-5533

Melyssa Kellyane Cavalcanti

Galdino ${ }^{2}$

(1) https://orcid.org/0000-0001-7180-3458

Selene Cordeiro Vasconcelos

그 https://orcid.org/0000-0002-8828-1251

Jayston W. J. Soares Neves ${ }^{3}$

(1) https://orcid.org/0000-0002-2163-5094

Murilo Duarte da Costa Lima

(D) https://orcid.org/0000-0002-1083-5517

\section{Executive functions and emotion regulation in substance use disorder}

\author{
Funções executivas e regulação emocional no transtorno por uso de substâncias
}

DOI: 10.1590/0047-2085000000331

\begin{abstract}
Objective: The executive functions (EF) and emotion regulation (ER) and their relationship with the substance use disorder (SUD) were analyzed. Methods: A cross-sectional design was used. The sample consisted of 130 volunteers divided into three groups: group $01(n=60)$, composed of participants who did not meet the diagnostic criteria for any type of SUD; group $02(n=51)$, with users with alcohol and/ or tobacco use disorder; group 03 ( $n=19$ ), with users with multiple substance use disorder, including at least one illicit substance. Results: Group 02 presented worse performance in EF and ER when compared to group 01, and showed a significant correlation between the working memory and the use of maladaptive ER. Group 03 showed great losses in EF and ER when compared to the other groups. Conclusion: This study supports the idea that EF, ER and SUD are related. In addition, it was observed that people with SUD had worse performance in EF and ER when compared to people without SUD, greater damage being observed in people with SUD of polysubstances.
\end{abstract}

\section{KEYWORDS}

Executive functions, emotion regulation, substance use disorder, drug, drug users.

\section{RESUMO}

Objetivo: Analisaram-se as funções executivas (FE) e a regulação emocional (RE) e a sua relação com o transtorno por uso de substâncias (TUS). Métodos: Utilizou-se um delineamento transversal. A amostra foi composta por 130 voluntários, divididos em três grupos: grupo 01 ( $n=60)$, composto pelos participantes que não preenchiam os critérios diagnósticos para nenhum tipo de TUS; grupo $02(n=51)$, com os entrevistados com TUS de álcool e/ou cigarro; grupo 03 ( $n=19)$, com os voluntários com TUS de polissubstâncias, incluindo pelo menos uma substância ilícita. Resultados: O grupo 02 apresentou pior desempenho nas FE e na RE, quando comparado ao grupo 01, e exibiu uma correlação significativa entre a memória de trabalho e o uso de RE desadaptativa. O grupo 03 apresentou maior prejuízo nas FE e na RE, quando comparado aos demais grupos. Conclusão: Este estudo apoia a ideia de que as FE, a RE e o TUS estão relacionados. Além disso, observou-se que as pessoas com TUS apresentaram pior desempenho nas FE e na RE, quando comparadas com as pessoas sem o TUS, sendo as com TUS de polissubstâncias com maior prejuízo.

\section{PALAVRAS-CHAVE}

Funções executivas, regulação emocional, transtorno por uso de substâncias, drogas, usuários de drogas.
Received in: Mar/4/2020. Approved in: Apr/6/202

1 Universidade Federal de Pernambuco (UFPE), Departamento de Neuropsiquiatria, Recife, PE, Brasil.

2 Universidade Federal da Paraíba (UFPB), Departamento de Psicologia, João Pessoa, PB, Brasil

3 Universidade Federal da Paraíba (UFPB), Departamento de Enfermagem em Saúde Coletiva, João Pessoa, PB, Brasil

Address for correspondence: Mariana Bandeira Formiga. Telefone: +55 (83) 98745-4044. E-mail: marianabandeiraf@gmail.com 


\section{INTRODUCTION}

Executive functions (EF) are essential skills for the development of human beings in cognitive, social and psychological aspects'. Some researchers consider an EF as a unitary process, while others suggest it is a multidimensional concept formed by related and independent abilities ${ }^{2}$. This article presents research results based on the multidimensional concept, according to Diamond's theory', which considers that the EF is formed by three main nuclei: inhibitory control (IC), working memory (WM) and cognitive flexibility (CF). The IC enables the person to resist to impulses or automatic habits according to appropriate behaviors and aligned with personal or social goals; the WM keeps information in mind and manipulates it, and may even evoke its own goals to assist the IC, while CF allows us to act creatively and to elaborate new perspectives, being flexible to adapt when changes emerge'.

Drug users who meet the criteria for substance use disorder (SUD) presented impaired performance in alcoholrelated $\mathrm{EF}^{3,4}$, tobacco ${ }^{5}$, marijuana ${ }^{6}$ and cocaine $^{7}$ when compared to healthy controls. However, it is still a challenge for science to infer the consequences of using only one drug in EF, since most users use alcohol or tobacco alone, or switch to polysubstances, including at least one illicit drug. In this sense, research has been carried out evaluating EF in multiusers, who also showed deficits when compared to nonusers $^{8,9}$. A study compared a control group, people with SUD (alcohol) and people with SUD (alcohol and other substances), in which the latter group performed unfavorably in EF and also in the process of emotional regulation ${ }^{10}$.

Emotion regulation, according to Gross ${ }^{11}$, is the process of modifying the intensity, duration or type of emotional response to maintain adaptive behaviors. The strategies used to regulate the emotions, according to the author mentioned, can be the up and down regulation, when they aim to reduce or to increase the effects of the emotions, respectively ${ }^{12}$. Based on this premise, Nelis et al..$^{13}$ proposed that ER strategies may be adaptive, functional, maladaptive or dysfunctional. In contexts that elicit positive emotions, ER strategies may be adaptive or maladaptive, as they increase or decrease the effects of these emotions, respectively. In scenarios that trigger negative emotions, they may be functional or dysfunctional, by decreasing or increasing the effects of these emotions, in this order ${ }^{13,14}$.

The difficulties in the ER are associated with the consumption of drugs 15,16 , with the emergence and maintenance ofSUD ${ }^{17,18}$ and the intense desire to consume ${ }^{17,19}$. In this perspective, it is understood that individuals with SUD use drugs to temporarily relieve their desire, thus generating a vicious cycle of increasing desire and $\mathrm{use}^{18}$ and that, after several years of consumption, substance use constitutes the main strategy of $\mathrm{ER}^{19}$.
The executive functions and the emotion regulation are closely associated ${ }^{20-22}$ and better skills in one area are associated with the better performance in another ${ }^{20}$ and both suffer losses when there is SUD ${ }^{23}$. It is conjectured that strong abilities in EF protect the person against the early start of substance use $\mathrm{e}^{24}$ and ER skills help maintaining abstinence during treatment and in the first few months after treatment ${ }^{16}$.

The losses in EF and ER influence the treatment and recovery of people with SUD. Deficits in EF and ER in users represent a risk of beginning drug use and facilitate the transition from recreational use to SUD ${ }^{25}$, negatively influencing treatment adherence and $u \mathrm{~s}^{26}$ and interfering in the motivational stage to change addictive behavior ${ }^{3}$. Knowing the extent of these damages helps to infer the possibilities of treatment, diagnosis, prognosis and monitoring of the evolution of the condition ${ }^{26}$.

Despite the literature on the effects of drug use in the $E F$ and $E R$, there are few studies covering the relationship of the two variables concomitantly in users. The main objective of this study was to analyze the executive functions and the emotion regulation and their relationship with the substance use disorder. It should be noted that this research presents the differential of comparing the results of people with alcohol use disorder and/or smokers with polysubstance users and monosubstance users who did not meet the criteria for SUD. Another aim was to understand the correlation between ER strategies (adaptive, maladaptive, functional or dysfunctional strategies) with the EF (IC, WM or CF).

\section{METHODS}

\section{Research design}

This is a cross-sectional with quantitative approach and nonprobabilistic sampling of intentional type.

\section{Research location}

Data collection with people with SUD was carried out in two Psychosocial Care Centers for Alcohol and Other Drugs (CAPSad), which are reference centers specialized in the treatment of drug users, in the metropolitan region of João Pessoa, Paraíba, Brazil. CAPSad offers support to users with SUD, regardless of the type and number of substances, with the aim of reducing the damages. Data collection of the volunteers without SUD was performed in a place previously scheduled according to the choice and availability of the participant.

\section{Population and sample}

Volunteers without SUD were recruited for convenience and their own interest, from the publicization of the 
research in social media, in higher education institutions and by the interviewees who disseminated the research to other people. Participants with SUD were recruited in the institutions surveyed. Data collection with participants with SUD was composed of all those who attended the institution weekly during the collection period, who were willing to participate and who were in accordance with the inclusion and exclusion criteria.

Data collection was carried out by a team composed of four researchers: a psychologist with experience in the clinical care of drug users, specialization and master's degree in the area, and three students in the last year of the psychology course. Before the collection, the team conducted studies and discussions about the instruments to be used, the psychologist trained the team for the proper use of the instruments and the students practiced the application of the instruments. There was a leveling to reach the gold standard, in which the team interviewed the same volunteers and obtained similar results. These volunteers are not included in the sample, as the collection of these data was only for training and leveling the team.

Volunteers $(n=136)$ were interviewed, however data of 6 participants with SUD were removed because they did not reach the cutoff point in the Mini-Examination of Mental State instrument. In this sense, the sample made up of 130 volunteers, divided into three groups, was analyzed. Group $01(n=60)$, named as non-SUD, comprised of participants who did not meet the diagnostic criteria for any type of SUD, but who could be alcohol users $(n=41)$ or tobacco $(n=19)$. Group $02(n=51)$, with volunteers with alcohol use disorder only $(n=14)$ or alcohol and tobacco use disorder $(n=37)$. And group $03(n=19)$, with users with multiple substance use disorder, including at least one of the illicit substances, named polysubstance users. In group $03,80 \%(n=15)$ were alcohol dependent, 57.9\% $(n=11)$ were dependent on marijuana or derivatives, $47.3 \%(n=9)$ were dependent on cocaine/crack and $42,1 \%(n=8)$ were dependent on cigarettes and derivatives.

\section{Criteria for inclusion and exclusion of the sample}

Volunteers older than 18 years and of both sexes, who did not meet the criteria for any SUD who had SUD for alcohol and/or tobacco use, or who had SUD related to multiple substances were the participants of the research. The criteria for the diagnosis of SUD were based on the Diagnostic and Statistical Manual of Mental Disorders (DSM-5) ${ }^{27}$ To reduce the risk of response bias, those with a score lower than 20 on the Mini-Mental State Examination ${ }^{28}$ were excluded and classified as having cognitive deficit, as it may interfere in the proper application of the instruments used, also volunteers with a current psychotic outbreak or who were under the effect of drugs at the time of collection.

\section{Procedure and instruments}

Data collection began after the signing of the informed consent form (ICF), carried out through an individual interview with an average duration of fifty minutes in an air-conditioned room. The instruments used were: sociodemographic questionnaire; Mini-Mental State Examination, in order to assess any presence of cognitive deficit ${ }^{28}$; Emotion Regulation Profile (ERP), to investigate adaptive and maladaptive, functional and dysfunctional emotion regulation strategies ${ }^{29}$; The Trail Making Test, part B, used to measure cognitive flexibility ${ }^{30}$ Stroop test, part $C$, to check inhibitory control; The Digits subtest in the WISC-III to evaluate working memory ${ }^{31}$; I -Structured Clinical Interview for DSMIV, to track psychiatric disorders and the risk of suicide ${ }^{32}$. Nine distinct classes of SUD (alcohol, tobacco, cannabis, hallucinogens, inhalants, opioids, stimulants, amphetamines and sedatives, hypnotics and anxiolytics) were investigated based on criteria established by the Diagnostic and Mental Disorders Statistics-5 (DSM-5), through a clinical interview. DSM-5 classifies SUD according to severity on three levels: mild, moderate and severe.

\section{Statistical analyzes}

Descriptive and inferential statistics were performed using the SPSS - Statistical Package for Social Sciences, version 22 (IBM, SPSS, version 22). Descriptive statistics were calculated from frequencies for sociodemographic variables according to the groups. Association was made among sociodemographic variables by means of the Chi-square test $\left(X^{2}\right)$.

In the analysis of the executive functions, the mean time for the execution of the inhibitory control and cognitive flexibility tests and the sum of the scores obtained in the working memory tests were considered. As it was a crosssectional study, the means of these tests were compared among the groups studied, rather than comparing them to the normative data, which are intended for clinical case studies, in which the clinical result is compared to the normative data of the population. In this case, one-way ANOVA was used to compare the executive functions among the three groups, followed by the Bonferroni test as post hoc.

Emotion regulation was analyzed considering the factors of the questionnaire, the dysfunctional, functional, maladaptive and adaptive regulation. One-way ANOVA was used to evaluate the difference among the groups in the type of strategy used, and then the Bonferroni Post Hoc test was used to analyze the comparisons of the groups in pairs. Bonferroni correlations were performed.

In the analysis of the executive functions and emotion regulation of the groups, Pearson's correlation tests were applied. In this case, the means of time in the tests of inhibitory control and cognitive flexibility, the sum of the scores obtained in the tests of working memory and the factors of the emotional regulation scale were considered. 


\section{Ethical aspects}

This research followed the guidelines of the National Health Council, Resolution No. 466, of December 12, 2012, on research involving human beings, being approved by the Ethics Committee, CAAE no 62521916.6.0000.5208.

\section{RESULTS}

\section{Sample characteristics}

The sample consisted of 130 participants, divided into three groups as described in the method. The mean age of the groups was 27 years (SD \pm 11 ), 36 (SD \pm 11 ) and 33 (SD \pm 8 ), respectively. The other sociodemographic characteristics are described in Table 1.

\section{Performance in executive functions by group}

The EF presented statistically significant results when compared to the performance of groups, as shown in Table 2 . Worse performance was observed in the groups with SUD (group 02 and group 03) in all tests when compared to nonSUD (group 01). Among the groups with SUD, group 03 had the worst result.
One-way ANOVA was used, which detected that there are significant differences among all groups in relation to the inhibitory control, STROOP C $[F(2.127)=6.64, p=0.05]$; in the WM, direct order digit span task (DOT) $[\mathrm{F}(2,127)=5,64$, $0.05]$, indirect order digit span task (IOT) $[\mathrm{F}(2.127)=10.37, \mathrm{p}$ $<0.05]$, and in the cognitive flexibility, part B of Trail Making Test (TMTB) [F $(2,66)=8,6, \mathrm{p}<0,05]$.

Regarding the inhibitory control (IC), significant results were observed in which the groups with SUD (groups 02 and 03) performed worse in the STROOP C test compared to group 01. Group 01 was faster in solving this test with 10.57 and 14.37 seconds less than groups 02 and 03, respectively.

In direct and indirect working memory tests, group 1 showed better performance than participants with SUD (group 02 and group 03). In both tests the score of group 01 was higher, being in the DOT with 1.66 and 1.92 and in the IOT with 2.03 and 2.33 points more than the groups 02 and 03 , respectively.

Regarding cognitive flexibility (CF), the best performance was in group 01, through the post hoc analysis of the TMT B test. Group 1 was faster than groups 02 and 03 with 63.08 and 88.87 seconds less to complete the task, respectively.

Table 1. Characterization of the sample

\begin{tabular}{|c|c|c|c|c|c|}
\hline & Group 01 & Group 02 & Group 03 & & \\
\hline & $\begin{array}{c}\text { Non-SUD } \\
\text { Fr (\%) }\end{array}$ & $\begin{array}{c}\text { SUD - alcohol and/or } \\
\text { tobacco } \\
\text { Fr (\%) }\end{array}$ & $\begin{array}{c}\text { TUS - poly substance } \\
\text { users } \\
\text { Fr (\%) }\end{array}$ & $x^{2}$ & $\mathbf{P}$ \\
\hline \multicolumn{6}{|l|}{ Gender } \\
\hline Male & $22(31,4)$ & $34(48,6)$ & $14(20)$ & 13,50 & $0,001^{*}$ \\
\hline \multicolumn{6}{|l|}{ Female } \\
\hline Marital status & $38(63,3)$ & $17(28,3)$ & $5(8,3)$ & & \\
\hline No relationship & 47 (47\%) & 38 (38\%) & $15(15 \%)$ & 6,41 & 0,379 \\
\hline In a relationship & $13(43,5 \%)$ & $13(43,5 \%)$ & $4(13 \%)$ & & \\
\hline \multicolumn{6}{|l|}{ Religion } \\
\hline Catholic & $33(46,5)$ & $32(45,1)$ & $6(8,5)$ & 9,53 & 0,146 \\
\hline Evangelical & $16(51,6)$ & $7(22,6)$ & $8(25,8)$ & & \\
\hline No religion & $11(40,7)$ & $11(40,7)$ & $5(18,5)$ & & \\
\hline Another religion & $0(0)$ & $1(100)$ & $0(0)$ & & \\
\hline \multicolumn{6}{|l|}{ Occupation } \\
\hline Student & $42(75)$ & $12(23,5)$ & $2(3,6)$ & 38,20 & $0,001^{*}$ \\
\hline Employed & $11(35,5)$ & $15(48,4)$ & $5(16,1)$ & & \\
\hline Unemployed & $5(16,1)$ & $17(54,8)$ & $9(29)$ & & \\
\hline Retired & $2(25)$ & $4(50)$ & $2(25)$ & & \\
\hline Informal work & $0(0)$ & $3(75)$ & $1(25)$ & & \\
\hline \multicolumn{6}{|l|}{ Formal education in years } \\
\hline Up to 9 years & $7(16,8)$ & $22(52,3)$ & $13(30,9)$ & 29,47 & $0,001^{*}$ \\
\hline Between 10 and 13 years & $11(44)$ & $11(44)$ & $3(16)$ & & \\
\hline More than 14 years & $42(53)$ & $18(25,3)$ & $11(15,4)$ & & \\
\hline
\end{tabular}

${ }^{*} p<0,05$ 


\section{Emotional regulation in groups}

Regarding the use of ER strategies (Table 3), a tendency of the sample to use more adaptive strategies elicited in scenarios that evoke positive emotions was evidenced. Regarding the use of dysfunctional and maladaptive strategies, the groups with SUD (group 02 and group 03) showed a higher frequency in the use of these strategies than the non-SUD group (group 01). Group 03 had the worst ER.

In the dysfunctional regulation strategy, significant differences were found between groups 01 and 02 and between groups 01 and 03. The group 02 obtained a difference of 1.2 in the score indicating greater use of dysfunctional regulation than group 1, while Group 03 presented a difference of 1.4 in the score of this factor, indicating greater use of this strategy than group 1 . When compared to group 01, group 02 showed a difference of 0.7 in the score of Maladaptive Regulation and group 03 a difference of 1.2, showing the greater use of this strategy by users with SUD when compared to non-SUD.

\section{Executive functions and emotion regulation in drug users}

The EF and ER were significantly correlated in the groups without SUD (group 01) and with SUD by alcohol and/or tobacco (group 02), however it was not observed in group 03.

In group 01, it was observed (Table 4) that the use of dysfunctional ER strategies presented weak negative correlations with the IC (STROOP C) and CF (TMTB), with coefficients -0.36 and -0.37 , respectively. This correlation indicates that when the performance in IC and CF increases, the use of dysfunctional ER strategies decreases or that when the use of these ER strategies increases, performance in IC and CF decreases.

Significant results were observed in group 02, (direct and indirect order) WM and the maladaptive ER strategy, according to Table 5. There were two significant negative correlations, with a variance of approximately $14 \%$ in both cases. This indicates that when one of the variables increases, the other decreases, that is, if WM is more preserved, there is less use of maladaptive ER strategy, or, if there is more use of maladaptive ER, the performance of WM will be lower.

Table 2. Comparisons of group performance in executive function tests

\begin{tabular}{lccccc}
\hline & $\begin{array}{c}\text { Group 01 } \\
\text { Non-SUS } \\
\text { AV (SD) }\end{array}$ & $\begin{array}{c}\text { Group 02 } \\
\text { SUD - alcohol and/or } \\
\text { tobacco } \\
\text { AV (SD) }\end{array}$ & $\begin{array}{c}\text { Group 03 } \\
\text { SUD - poly substance } \\
\text { users } \\
\text { AV (SD) }\end{array}$ & F & P $<$ 0,05 \\
\hline STROOP C & $26,53(14,78)$ & $37,1(22,42)$ & $40,9(17,77)$ & 6,64 & $0,002^{* *}$ \\
DOT & $9,72(2,91)$ & $8,06(3,22)$ & $7,8(2,14)$ & 5,64 & $0,004^{* *}$ \\
IOT & $5,93(2,64)$ & $3,9(2,7)$ & $3,6(2,54)$ & 10,37 & $0,001^{* *}$ \\
TMT.B & $98,93(83,38)$ & $162,01(113,32)$ & $187,8(102,88)$ & 8,61 & $0,001^{* *}$ \\
\hline
\end{tabular}

${ }^{*} \mathrm{p}<0,05 ;{ }^{* \star} \mathrm{p}<0,01$; AV: average; SD: standard deviation; Md: median; DOT: direct order digit span task; IOT: indirect order digit span task; TMT.B: Trail Making Test.

Table 3. Frequency of the strategies of emotion regulation used by the groups

\begin{tabular}{lccccc}
\hline & $\begin{array}{c}\text { Group 01 } \\
\text { Non-SUD } \\
\text { AV (SD) }\end{array}$ & $\begin{array}{c}\text { Group 02 } \\
\text { SUD - alcohol and/or } \\
\text { tobacco } \\
\text { AV (SD) }\end{array}$ & $\begin{array}{c}\text { Group 03 } \\
\text { SUD - poly substance } \\
\text { users } \\
\text { AV (SD) }\end{array}$ & F & P< 0,01 \\
\hline Dysfunctional regulation & $2,3(0,91)$ & $3,5(1,29)$ & $3,6(1,41)$ & 17,7 & $0,000^{* *}$ \\
Functional regulation & $4,1(0,9)$ & $4,2(0,86)$ & $4,3(0,73)$ & 0,58 & 0,773 \\
Maladaptive regulation & $2,6(1,08)$ & $3,3(1,32)$ & $3,5(1,39)$ & 7,24 & $0,001^{* *}$ \\
Adaptive regulation & $5(0,77)$ & $5,06(0,86)$ & $4,7(0,97)$ & 1,09 & 0,337 \\
\hline
\end{tabular}

Table 4. Correlation matrix of executive functions, emotion regulation strategies and group 01

\begin{tabular}{lcccc} 
& Dysfunctional regulation & Functional regulation & Maladaptive regulation & Adaptive regulation \\
\hline STROOP C & $-0,36^{* *}$ & 0,19 & $0,26^{*}$ & 0,12 \\
DOT & 0,2 & $-0,07$ & $-0,32$ & 0,06 \\
IOT & 0,25 & $-0,27^{*}$ & $-0,21$ & $-0,02$ \\
TMT.B & $-0,37^{* *}$ & 0,24 & 0,12 & 0,05 \\
\hline
\end{tabular}

${ }^{*} \mathrm{p}<0,05$; ${ }^{* \star} \mathrm{p}<0,01$; AV: average; SD: standard deviation; Md: median; DOT: direct order digit span task; IOT: indirect order digit span task; TMT.B: Trail Making Test. 
Table 5. Matrix of correlation of executive functions, strategies of emotion regulation and consumption of licit substances

\begin{tabular}{lcccc}
\hline & $\begin{array}{c}\text { Dysfunctional } \\
\text { regulation }\end{array}$ & Functional regulation & $\begin{array}{c}\text { Maladaptive } \\
\text { regulation }\end{array}$ & Adaptive regulation \\
\hline STROOP C & 0,09 & 0,1 & 0,23 & 0,14 \\
DDP & $-0,00$ & $-0,09$ & $-0,38^{\star}$ & $-0,11$ \\
DIP & $-0,06$ & $-0,06$ & $-0,37^{*}$ & $-0,12$ \\
TMT.B & 0,18 & $-0,00$ & 0,22 & $-0,00$ \\
\hline
\end{tabular}

* $\mathrm{p}<$ 0,05; AV: average; SD: standard deviation; Md: median; DOT: direct order digit span task; IOT: indirect order digit span task; TMT.B: Trail Making Test.

\section{DISCUSSION}

The results of this research point out that substance use disorder (SUD), executive functions (EF) and emotional regulation (ER) are correlated with each other, corroborating with previous research ${ }^{33-35}$. It was observed that people with SUD had worse performance in EF and more use of dysfunctional and maladaptive ER strategies when compared to people without SUD, confirming previous results 3,7,8,15,16,36.

Participants with SUD (group 02 and group 03) showed impairments in EF when compared to those without SUD (group 01), with polysubstance users (group 03) having the worst performance. In this sense, researchers verified that alcohol consumption resulted in memory damage, losses in visual perception, lower problem-solving capacity and less mental flexibility ${ }^{37}$ and even the social drinkers showed signs of EF alterations ${ }^{38}$. In another study, polysubstance users presented generalized deficits in EF, such as WM, inhibition, cognitive flexibility, self-regulation and decision making'. In addition, polysubstance users, when compared to people with SUD of only one substance, presented worse prognosis, earlier onset of consumption, higher rates of treatment abandonment ${ }^{39}$ and higher prevalence of psychiatric comorbidities ${ }^{40}$.

Emotional regulation was more frequent in all groups in the use of adaptive strategies, which are related to contexts that evoke positive emotions, and the use of these strategies indicates a tendency in the ability to deal with positive emotions. Despite the evident consumption of drugs in celebrations, festivities and in the seek for pleasure, it is the negative emotion that is associated with relapses, the desire to consume, the attention focused on signs related to consumption and the greater probability of using substances as a mechanism to face problems ${ }^{41}$. These findings support the negative reinforcement model of dependence ${ }^{42}$, where substance use occurs in order to avoid negative affective states caused by drug absence.

It was found that the use of maladaptive and dysfunctional strategies increased in relation to the groups studied, in which group 01 had the least use and group 03 the most use of these strategies. Significant results of emotional impairment were observed in relation to SUD (group 02 and group 03), and the polysubstance users (group 03), again, showed worse results. ER difficulties, such as limited access to strategies and suppression of thinking, are related to the negative effect of craving ${ }^{19}$. Alcohol users presented greater problems with ER in comparison to social users ${ }^{43}$. Polysubstance users with difficulty in ER were related to early drug use, injectable use and more serious problems of dependence ${ }^{44}$. On the other hand, the use of effective ER strategies was associated with lower drug use in a sample of cocaine users being treated ${ }^{45}$. In this scenario, the inability to regulate emotions makes it difficult to change behavior ${ }^{46}$, which may help to explain the tendency to continue using drugs even in the face of known negative results ${ }^{47}$

Maladaptive ERand WMare correlated with alcohol and/or tobacco use in this sample. As EF are made up of three related and independent nuclei ${ }^{1}$ it is feasible that only the working memory is significantly related to another variable. Previous research corroborates the significant results between WM and $E R^{22,48}$, confirm the losses of alcohol consumption in $E^{16}$ and in the $\mathrm{WM}^{49}$ and ratify the correlation among WM, ER and alcohol use disorder ${ }^{33}$ and cigarette smoking ${ }^{18}$. It is important to note that the higher the doses of alcohol consumption, the lower the performance in the WM and the lower the capacity to manage consumption ${ }^{49}$. In addition, the positive and rewarding effects of alcohol are associated with greater propensity to remember these pleasant stimuli related to consumption, which may influence their drinking behavior ${ }^{50}$ However, poor performance in the WM makes it harder for people to keep in mind why they are drinking ${ }^{49}$ which alerts the behavior of continuing to drink automatically, exacerbating the challenge of inhibiting consumption or of having a moderate use.

ER plays a crucial role in the development, severity, treatment and prognosis of SUD, and cognitive deficits also negatively impact SUD ${ }^{51}$. A promising approach in the treatment of addiction is mindfulness, which helps people with SUD to improve behavioral self-control through better regulation of emotions emotions ${ }^{52}$. Interventions based on mindfulness, when compared to traditional interventions, resulted in a significantly lower risk of relapse in substance use and excessive alcohol consumption. Mindfulness acts as a tool that helps to strengthen the ability to observe and deal 
with the discomfort associated with the desire or negative affect, generating an impact on the control of substanceconsuming behavior and achieving positive and long-term results in the treatment of SUD ${ }^{53}$.

Scientific support which base the importance of interventions in emotion regulation and in the three nuclei of executive functions, inhibitory control, working memory and cognitive flexibility are listed. First, in the absence of an appropriate IC, the SUD easily perpetuates itself in a vicious cycle of abstinence, craving, compulsion, intoxication, and relapse ${ }^{54}$. Second, a hallmark of successful ER is the ability to inhibit behavioral responses such as habits and impulses that are incompatible with personal goals. Third, WM supports the mental representation of the goals and the means of achieving them, supporting proactive forms of $E R$, allowing individuals to resist tempting stimuli related to substance use. The preserved WM allows recall of the goals which induces behaviors consistent with these goals, while the limited WM increases the occurrence of automatic and impulsive actions. Fourth, cognitive flexibility provides the ability to change behaviors that, while aligned with goals, are not compatible with the user's abilities and possibilities ${ }^{55}$.

Despite the losses in EF and ER related to long-term drug use, the present research is concluded with a motivating perspective. First, the ER is capable of lifelong changes, because it has continuous development ${ }^{48}$, so when there are changes in a person's life context and different forms of coping with everyday situations are required, these new experiences play a primordial role and allow ER processes to be shaped ${ }^{56}$. Second, neuroimaging research supports the hypothesis that people with SUD can recruit mechanisms of inhibitory control mediated by the prefrontal cortex to suppress drug craving ${ }^{57,58}$ and these mechanisms of resistance to consumption suggest a significant degree of cognitive flexibility ${ }^{59}$.

The results of this research provide an updated picture of the reality of consumption, which consists of the exclusive use of alcohol, associated or not with cigarettes, and of polysubstance users, including at least one illicit substance, and of their emotional and cognitive impairments. This study described correlations between EF, ER and SUD, however, because it is a cross-sectional study, there are no causal inferences.

The limitations of this study focus on: a) the small number of users with disorders due to the use of polysubstances, including illicit drugs; $b$ ) the difference in the variables of age and years of schooling among the groups; $c$ ) and because there was no control over the variables of substance use time and psychiatric comorbidities. With regard to the reduced number of the group of polysubstance users, it is noteworthy that the data collection involved all users with SUD of polysubstances who attended the two CAPSads weekly during the data collection period, who were willing and able to participate in the study. Regarding the limitation of schooling, to minimize the interference of this variable, it was decided to include only volunteers who obtained a score equal to or greater than twenty points in the MiniMental State Examination instrument, so as to exclude those with cognitive deficits. It is suggested that future research expand the sample and carry out longitudinal studies, which can deepen the correlations obtained in this study.

\section{CONCLUSION}

This study supports the idea that executive functions (EF), emotional regulation (ER) and substance use disorder (TUS) are related. Participants with SUD had lower performance in EF and worse ER when compared to those without SUD. Volunteers with SUD related to polysubstances (including illicit substances) were those who exhibited the greatest damage. Worst performance in WM and higher maladaptive ER strategies are observed in people with SUD in comparison to those without SUD.

\section{INDIVIDUAL CONTRIBUTIONS}

All authors contributed significantly to the conceiving of the study, methodological approach, analysis and interpretation of the data, as well as in the elaboration of the article, revision of the content and approved the final version to be published.

\section{CONFLICT OF INTERESTS}

The authors report no conflicts of interest.

\section{REFERENCES}

1. Diamond A. Executive Functions. Annu Rev Psychol. 2013;64:135-68.

2. Garcia-Andres E, Huertas-Martínez JA, Ardura A, Fernández-Alcaraz C. Emotion regulation and executive function profiles of functioning related to the social development of children. Procedia Soc Behav Sci. 2010;5:2077-81.

3. Rigoni MS, Susin N, Trentini CM, Oliveira MS. Alcoolismo e avaliação de funções executivas: uma revisão sistemática. Psico. 2012;44(1):122-9.

4. Day AM, Kahler CW, Ahern DC, Clark US. Executive Functioning in Alcohol Use Studies: A Brief Review of Findings and Challenges in Assessment. Curr Drug Abuse Rev. 2015;8(1):26-40.

5. Durazzo TC, Meyerhoff DJ, Nixon SJ. A comprehensive assessment of neurocognition in middle-aged chronic cigarette smokers. Drug Alcohol Depend. 2012;122(1-2):105-11.

6. Mchale S, Hunt N. Executive function deficits in short-term abstinent cannabis users. Hum Psychopharmacol Clin Exp. 2008;23:409-15. 
7. Woicik PA, Urban C, Alia-Klein N, Henry A, Maloney T, Telang F, Wang GJ, et al. A pattern of perseveration in cocaine addiction may reveal neurocognitive processes implicit in the Wisconsin Card Sorting Test. Neuropsychologia. 2011;49(7):1660-9.

8. Fernández-Serrano MJ, Pérez-García M, Schmidt Río-Valle J, Verdejo-García A. Neuropsychological consequences of alcohol and drug abuse on different components of executive functions. J Psychopharmacol. 2010;24(9):1317-32.

9. Moreno-López L, Stamatakis EA, Fernández-Serrano MJ, Gómez-Río M, RodríguezFernández A, Pérez-García M, et al. Neural correlates of hot and cold executive functions in polysubstance addiction: Association between neuropsychological performance and resting brain metabolism as measured by positron emission tomography. Psychiatry Res. 2012:203(2-3):214-21.

10. Lewis B, Garcia CC, Bohan R, Nixon SJ. Impact of polysubstance use on social and nonaffective cognitive performance among treatment-seeking individuals with alcohol use disorders. Addict Behav. 2020;106:106359.

11. Gross JJ. Antecedent- and response-focused emotion regulation: Divergent consequences for experience, expression, and physiology. J Pers Soc Psychol. 1998;74(1):224-37.

12. Gross JJ. Emotion Regulation: current status and future prospects. Psychol Inq. 2015;26(1):1-26

13. Nelis D, Quoidbach J, Hansenne M, Mikolajczak M. Measuring individual differences in emotion regulation: The emotion regulation profile-revised (ERP-R). Psychol Belg. 2011:51(1):49-91.

14. Gondim SMG, Pereira CR, Hirschle ALT, Palma EMS, Alberton GD, Paranhos J, et al. Evidências de Validação de uma Medida de Características Pessoais de Regulação das Emoções. Psicol Reflex Crit. 2015;28(4):659-67.

15. Fucito LM, Juliano LM, Toll BA. Cognitive reappraisal and expressive suppression emotion regulation strategies in cigarette smokers. Nicotine Tob Res. 2010;12(11):1156-61.

16. Berking M, Margraf $M$, Ebert D, Wupperman P, Hofmann SG, Junghanns K. Deficits in emotion-regulation skills predict alcohol use during and after cognitive-behavioral therapy for alcohol dependence. J Consult Clin Psychol. 2011;79(3):307-18.

17. Petit $G$, Luminet 0 , Maurage $F$, Tecco J, Lechantre $S$, Ferauge $M$, et al. Emotion Regulation in Alcohol Dependence. Alcohol Clin Exp Res. 2015;39(12):2471-9.

18. Kober H. Emotion regulation in substance use disorders. In: Gross JJ, editor. Handbook of emotion regulation. New York: Guilford Press; 2015. P. 428-46.

19. Dias MTCL. A relação entre craving e sintomatologia em função da regulação emocional e da comorbilidade. Portugal: Universidade do Algarve; 2015

20. Anderson VA, Anderson P, Northam E, Jacobs R, Mikiewicz 0. Relationships between cognitive and behavioral measures of executive function in children with brain disease. Child Neuropsychol. 2002;8(4):231-40.

21. Pe ML, Raes F, Kuppens P. The cognitive building blocks of emotion regulation: ability to update working memory moderates the efficacy of rumination and reappraisal on emotion. PLoS One. 2013;8(7):e69071.

22. Sperduti M, Makowski D, Arcangeli M, Wantzen P, Zalla T, Lemaire S, et al. The distinctive role of executive functions in implicit emotion regulation. Acta Psychol (Amst). 2017:173:13-20.

23. Goldstein RZ, Volkow ND. Dysfunction of the prefrontal cortex in addiction: Neuroimaging findings and clinical implications. Nat Rev Neurosci. 2011;12(11):652-69.

24. Day AM, Kahler CW, Ahern DC, Clark US. Executive Functioning in Alcohol Use Studies: A Brief Review of Findings and Challenges in Assessment. Curr Drug Abuse Rev. 2015;8(1):2640.

25. George 0 , Koob GF. Individual differences in prefrontal cortex function and the transition from drug use to drug dependence. Neurosci Biobehav Rev. 2010;35:232-47.

26. Ferreira VRT, Colognese BT. Prejuízos de funções executivas em usuários de cocaína e crack. Aval Psicol. 2014;13(2):195-201

27. American Psychiatric Association. DSM-5 - Manual Diagnóstico e Estatístico de Transtornos Mentais. Porto Alegre: Artmed; 2014

28. Brucki SMD, Nitrini R, Caramelli P, Bertolucci PHF, Okamoto IH. Sugestões para o uso do mini-exame do estado mental no Brasil. Arq Neuro-Psiquiatr. 2003;61(3B):777-81.

29. Gondim SM, Pereira SR, Hirschle AL, Palma EM, Alberton GD, Paranhos JS, et al. Evidências de Validação de uma Medida de Características Pessoais de Regulação das Emoções. Psicol Reflex Crit. 2015;28(4):659-67.
30. Goul WR, Brown M. Effects of age and intelligence on trail making test performance and validity. Percept Mot Skills. 1970;30:319-26.

31. Nascimento E. Validação e adaptação do teste WAIS-III para um contexto brasileiro [Tese de Doutorado]. Brasília: Universidade de Brasília; 2000.

32. Amorin P. Mini International Neuropsychiatric Interview (MINI): validação de entrevista breve para diagnóstico de transtornos mentais. Rev Bras Psiquiatr. 2000;2:106-15.

33. Giancola P. Executive functioning and alcohol-related aggression. J Abnorm Psychol. 2004;113(4):541-55

34. Godlaski AJ. Identifying component-processes of executive functioning that serve as risk factors for alcohol-related aggression [Doctoral Dissertations]. Kentucky: University of Kentucky; 2011.

35. Verdejo-García A, Bechara A, Recknor EC, Pérez-García M. Executive dysfunction in substance dependent individuals during drug use and abstinence: An examination of the behavioral, cognitive and emotional correlates of addiction. J Int Neuropsychol Soc. 2006;12(3):405-15

36. Pentz MA, Riggs NR, Warren CM. Improving substance use prevention efforts with executive function training. Drug Alcohol Depend. 2016;163 Suppl 1:S54-9.

37. Feldens ACM, Silva JG, Oliveira MS. Avaliação das funções executivas em alcoolistas. Cad Saúde Coletiva. 2011;19:164-71.

38. Cunha PJ, Novaes MA. Avaliação neurocognitiva no abuso e dependência do álcool: implicações para o tratamento. Rev Bras Psiquiatr. 2004;26(1):23-7.

39. Preti E, Prunas A, Ravera F, Madeddu F. Polydrug abuse and personality disorders in a sample of substance-abusing inpatients. Ment Health Subst Use. 2011;4(3):256-66.

40. Formiga MB, Vasconcelos SC, Galdino-Cavalcanti MK, Lima MDC. Presence of dual diagnosis between users and non-users of licit and illicit drugs in Brazil. J Bras Psiquiatr. 2015;64(4):288-95.

41. Cheetham A, Allen NB, Yücel M, Lubman DI. The role of affective dysregulation in drug addiction. Clin Psychol Rev. 2010;30:621-34.

42. Kassel JD, Veilleux JC, Wardle MC, Yates MC, Greenstein JE, Evatt DP, et al. Negative affect and addiction. In: al'Absi M, editor. Stress and addiction: biological and psychological mechanisms. London: Academic Press; 2007.

43. Fox HC, Hong KA, Sinha R. Difficulties in emotion regulation and impulse control in recently abstinent people with alcohol use disorder compared with social drinkers. Addict Behav. 2008;33(2):388-94

44. Wong CF, Silva K, Kecojevic A, Schrager SM, Bloom JJ, Iverson E, et al. Coping and emotion regulation profiles as predictors of nonmedical prescription drug and illicit drug use among high-risk young adults. Drug Alcohol Depend. 2013;132:165-71.

45. Decker SE, Morie K, Hunkele K, Babuscio T, Carroll KM. Emotion regulation strategies in individuals with cocaine use disorder maintained on methadone. Am J Addict. 2016;25(7):529-32

46. Miranda R Jr, Meyerson LA, Buchanan TW, Lovallo WR. Altered emotion-modulated startle in young adults with a family history of alcoholism. Alcohol Clin Exp Res. 2002;26(4):441-8.

47. Bechara A. Risky business: emotion, decision-making, and addiction. J Gambl Stud. 2003;19(1):23-51.

48. Gross J. Emotion Regulation: Taking Stock and Moving Forward. Emotion. 2013;13(3):359-65.

49. Lechner WV, Day AM, Metrik J, Leventhal AM, Kahler CW. Effects of alcohol-induced working memory decline on alcohol consumption and adverse consequences of use. Psychopharmacology (Berl). 2016;233(1):83-8.

50. Weafer J, Gallo DA, Wit H. Effect of alcohol on encoding and consolidation of memory for alcohol-related images. Alcohol Clin Exp Res. 2016;40(7):1540-7.

51. Marceau EM, Kelly PJ, Solowij N. The relationship between executive functions and emotion regulation in females attending therapeutic community treatment for substance use disorder. Drug Alcohol Depend. 2018;182:58-66.

52. Tang YY, Tang R, Posner MI. Mindfulness meditation improves emotion regulation and reduces drug abuse. Drug Alcohol Depend. 2016;163 Suppl 1:S13-8.

53. Bowen S, Witkiewitz K, Clifasefi SL, Grow J, Chawla N, Hsu SH, et al. Relative Efficacy of Mindfulness-Based Relapse Prevention, Standard Relapse Prevention, and Treatment as Usual for Substance Use Disorders: A Randomized Clinical Trial. JAMA Psychiatry. 2014;71(5):547-56 
54. Li CS, Sinha R. Inhibitory control and emotional stress regulation: Neuroimaging evidence for frontal-limbic dysfunction in psycho-stimulant addiction. Neurosci Biobehav Rev. 2008;32(3):581-97.

55. Hofmann W, Schmeichel BJ, Baddeley AD. Executive functions and self-regulation. Trends Cogn Sci. 2012;16(3):174-80.

56. Gross JJ, Thompson RA. Emotion regulation: conceptual foundations. In: Gross JJ, editor. Handbook of Emotion Regulation. New York, NY: Guilford Press; 2007. p. 3-24.
57. Kober H, Kross EF, Mischel W, Hart CL, Ochsner KN. Regulation of craving by cognitive strategies in cigarette smokers. Drug Alcohol Depend. 2010;106(1):52-5.

58. Kober H, Mende-Siedlecki P, Kross EF, Weber J, Mischel W, Hart CL, et al. Prefrontalstriatal pathway underlies cognitive regulation of craving. Proc Natl Acad Sci U S A. 2010;107(33):14811-6.

59. Mihindou C, Guillem K, Navailles S, Vouillac C, Ahmed SH. Discriminative inhibitory control of cocaine seeking involves the prelimbic prefrontal cortex. Biol Psychiatry. 2013;73:271-9. 